\title{
25
}

\section{Parents' Resources for Facilitating the Activities of Children with Autism at Home}

\author{
Monica Ramey and John Rae
}

\section{Introduction}

In the United Kingdom, and in many societies, whatever level of support might be available outside the child's home, the primary carers for children with autism are often their own family members, usually their parents. Consequently, parents' resources for supporting their children's capacity to engage in activities are of considerable practical importance and merit careful analysis. Indeed, there is evidence from a randomised control study that a joint engagement programme can have a positive long-term effect on children's abilities (Kasari, Gulsrud, Wong, Kwon, \& Locke, 2010). A general aim of parents' participation in children's activities (including neurotypical children) is to enable children to achieve more than they could unaided. The importance of such coparticipation is captured by Vygotsky's influential idea of the zone of proximal development (ZPD). This refers to a region which is just beyond a child's current sphere of competence but into which the child can move through the involvement of a more experienced peer or carer. For Vygotsky's socio-cultural theory of learning, it is not merely that the child can achieve more with support but rather that such supportive encounters are fundamental for development. He states that the ZPD 'awakens a variety of internal developmental processes that are able to operate only when the child is interacting with people in his environment' (Vygotsky, 1978, p. 90). The term 'scaffolding' (Wood, Bruner, \& Ross, 1976) is a related metaphor that is widely used in learning environments to describe the supportive conduct. While Wood et al. (1976) do not cite Vygotsky, the intimate connection between scaffolding and Vygotsky's work is pointed out by Cazden (1979). It can be said that scaffolding is the support that is provided by a 'more knowledgeable other' who can assist the learner in completing a task or solving a problem by assisting the learner into the ZPD. In scaffolding, language and interaction are important as the child internalises routines 
and procedures from the social and cultural context where he or she learns (Applebee \& Langer, 1983). Tasks should build on what the child already knows and ongoing assessment of the child is important in order to tailor scaffolding as required (Langer \& Applebee, 1986). Additionally, dialogue in interaction keeps the recipient actively engaged in the activity and through monitoring both parties can coordinate the direction of the activity (Brown \& Palincsar, 1989).

Parents can take on the role of the facilitator providing strategies for completing a task. Additionally, parents are able to expand the child's learning by using modelling, perspective taking, clues, and pointing out important information that can help learners think (Wood et al., 1976). In Wood (1980, cited in Carr \& Pike, 2012), contingent shifting is used to describe change in the level of support offered depending on the child's performance, such as a reduction in the level of support in response to the child making progress. However, increasingly the responsibility for task completion is given to the child, thereby expanding his or her knowledge. Carr and Pike (2012) suggest that effective contingent shifting in scaffolding by the parent may be indirectly influenced by the parenting style in managing challenging behaviour and developing a positive relationship with the child. Although previous research into parents scaffolding their children's activities has used observational measures and has focused on specific areas of interactions that may affect educational and developmental outcomes (e.g. Carr \& Pike, 2012; Salonen, Lepola, \& Vauras, 2007), a study by Freeman and Kasari (2013) observed the scaffolding styles of parents of children with ASD during a ten-minute play session and found that parents of children with ASD created more play scenarios and offered and directed play more than parents of typical children. Parents of children with ASD also showed high interest in their child's play attempts, responding with high levels of play, while parents of typical children would expand their children's play. In conclusion, parents who were less directive and played just above the child's level, combined with imitating the child's actions, resulted in longer interactions.

These observational studies involve the careful coding of specific practices of parental scaffolding in order to examine scaffolding in a systematic way. Conversation Analysis (CA) offers a complementary research approach in which a more exploratory stance is taken to interaction and in which the organisation of interactional phenomena is the focus. A particular focus of CA research involves the delineation of the sequential relationship between one participant's action and another participant's action-in-response. A previous CA-based analysis of scaffolding examined the nature of a learning support assistant's (LSA) supportive conduct in a classroom setting (Stribling \& Rae, 2010). This case study of a single extended episode examined how the LSA co-participated in a number of sequences initiated by a class teacher in order to facilitate a response from a girl with autism. The interactional organisation of instructional settings has been examined quite extensively through CA methods; 
for example, there are multimodal analyses of object-related interactions in adult learning situations such as manual crafts (Ekström, Lindwall, \& Säljö, 2009; Lindwall \& Ekström, 2012) and surgery (e.g. Mondada, 2014; Zemel \& Koschmann, 2014).

For Vygotsky, the concept of the ZPD was fundamentally concerned with development; it provided a way of understanding how support from others can contribute to development. In a related way, the concept of scaffolding suggests a temporary supportive structure, one that can be removed in due course. In the case of atypical development, it is not necessarily the case that supportive behaviour can be withdrawn (Stone, 1998). It can be briefly noted that a related conceptualisation occurs within the Applied Behavior Analysis (ABA) or the Lovaas approach to teaching children with autism. Here, a trainer's or parent's support behaviours are construed as prompts. Based on the principles of operant conditioning, a common concern is the fading of these prompts such that the child can perform the socially relevant target behaviour independently (e.g. Krantz \& McClannahan, 1998; MacDuff, Krantz, \& McClannahan, 2001).

Given the importance of parental scaffolding and the need to understand what practices it consists in, this chapter uses CA to identify moment-to-moment actions in episodes on interaction involving children with autism and their parents carrying out spontaneous activities together at home.

\section{Project overview}

In order to examine the organisation of talk-in-interaction and scaffolding procedures provided by parents and children with an Autism Spectrum Disorder (ASD) taking part in naturally occurring interactions at home, families with children with ASD were emailed a letter of invitation to take part in the study. Parents who agreed and gave full informed consent were additionally provided with a debrief form with contact details if further information is needed or if they wish to withdraw. Our analysis is based on video-recordings of four children with an ASD to whom we shall refer using the following pseudonyms: Mary (aged 14) interacting with her Mum and doing pottery and poetry classes; Ben (aged 12) interacting with his Mum, Dad, and also with a sibling and an ABA tutor carrying out money-related activities, playing with Lego and playing with a video game; and Will and Anna (both aged 13), baking with Will's Mum. A total of two hours of video-recordings were made.

Different analytical approaches can be brought to bear on video data from learning settings (Barron, 2006). CA is applied for this study due to its focus on social interaction in its own terms. A notable early formulation of CA refers to the aim of developing '... a naturalistic observation discipline that could deal with the details of social action(s) rigorously, empirically and formally' (Schegloff \& Sacks, 1973, p. 233). This paper further states, 'Our analysis has sought to explicate the ways in which our materials are produced in 
orderly ways that exhibit orderliness and have orderliness appreciated and used...' (p. 290). This orderliness is frequently, but not exclusively, exhibited in the analysis of sequentially unfolding moment-by-moment interaction (Goodwin \& Heritage, 1990; Schegloff, 2007). Fundamentally then, CA takes stretches of interactional data and asks, first, what is the social organisation? Secondly, how is this organisation produced? It should be noted that CA originated within sociology and that often the basic sociological question of who is doing what? It is this that is relevant in the analysis. Indeed, although our focus is on domestic activities, in our analysis the classical sociological issues of the division of labour, who controls the means of production, and matters of identity will be relevant. While CA can be used to underpin quantitative Content Analytic studies which incorporate inter-rater agreement measures, it is, in the first instance, a qualitative discovery-oriented methodology.

Video-recordings were inspected in terms of what activities are underway and how they are organised. In addition to attending to the participants' talk and other vocalisations, their gaze, gesture, and handling of objects were frequently the focus of analysis. Video-recorded data can be especially useful for the analysis of interactions involving children with autism, as gaze and body language can be particularly pertinent (see Dickerson \& Robins, Chapter 4, this volume, for a good example). In this report then, we are primarily concerned with the parents' resources but in order to get them, the actions of both parents and children need to be examined. Episodes of interest were transcribed using the Jefferson transcription system for CA extended with annotations for visible action. While CA analysis commonly, and perhaps preferably, selects a specific interactional phenomenon and examines it in depth and detail, the present treatment locates a number of phenomena that are constitutive of the setting that is under analysis. The analysis here is geared to identifying the facilitating practices that occur, and how they are implemented, in a small opportunity sample.

\section{Analysis}

The analysis will first focus on a single extend episode, a pottery-making session, and identify a range of supportive actions within this. We will then consider the generality of some of the phenomena observed through comparisons with episodes involving other families in other settings. In the pottery session (which is of about 12-minutes duration), Mary fashions a clay pot, with help from her Mum, on a small battery-powered portable potter's wheel. The analysis will draw on a number of transcribed episodes within this activity. Readers should note that these extracts seek to represent the activity that occurred rather than to describe it. As such, readers are encouraged to try to visualise the unfolding actions. 


\section{Extract 1 [MR2012 MM Clay] simplified}

Mary is seated at a table with a potter's wheel in front of her with a tool in her right hand. Her mother is approaching the table and is beside Mary, placing a small water bowl on the table. Mary is turned to her right, towards her mother.

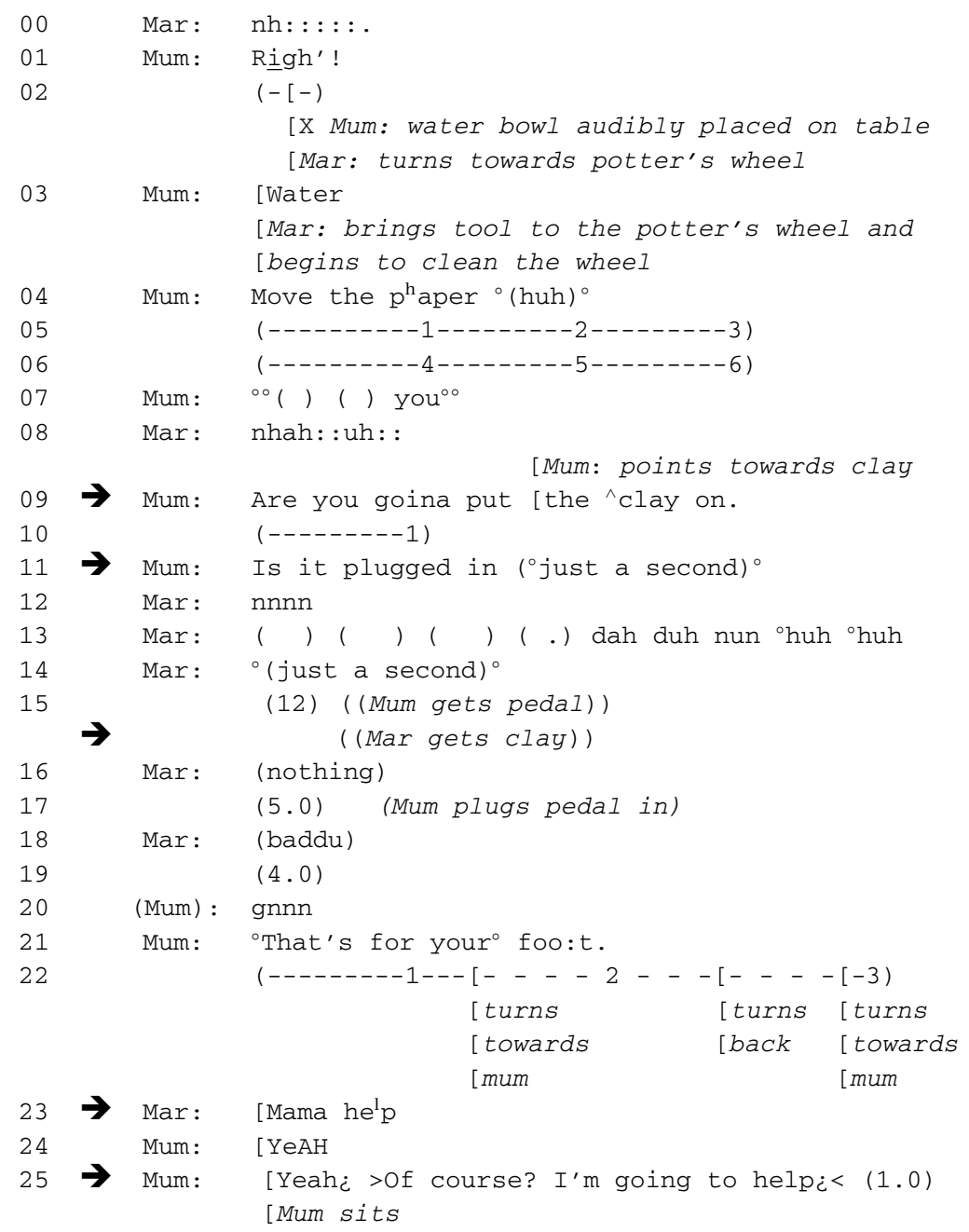

In Extract 1, Mum assists with some material preparations, commenting on them as she performs them: setting a bowl of water next to Mary (lines 2-3) and removing some irrelevant pieces of paper (line 4). When Mum sets the water down, Mary begins to scrape the potter's wheel with a clay-working tool. Mum produces an initiating action, 'Are you goina put the ^clay on.', pointing at the clay, which is apparently designed to progress the pottery activity, encouraging 
Mary to move from cleaning the wheel to getting the material to be worked on into position. Mary continues cleaning the wheel, but at this point the mother engages in another preparatory matter, namely the proper positioning of the pedal which controls the rotation of the potter's wheel. She launches this through a question, 'Is it plugged in ( ${ }^{\circ}$ just a second) $)^{\circ}$ and moves to get the pedal, to plug into the wheel, and she positions it on the floor. As Mum reaches for the pedal, which is on the table to Mary's left, Mary reaches for the clay, which is also to her left. As Mum unwraps the wire from the pedal, Mary unwraps the clay. As Mum becomes available after placing the pedal on the

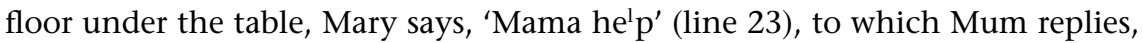
'Yeah $i>$ Of course? I'm going to help'.

The tape only begins with Mary already sitting at the table, so we do not have access, on video, to the background to this episode of activity. We can see, however, that Mum is engaged in a number of actions that are accountably designed to prepare for, and to progress, the activity of pottery. Some of these actions appear to be fundamentally unilateral, for example setting down the bowl of water next to Mary; however, it is notable that this is done in a conspicuous and accountable way - the arrival of the bowl to the table being accompanied by 'right', the occurrence of a loud clink as it meets the table, and the provision of verbal commentary on this, 'Water' (line 3) By contrast, the instruction to put the clay onto the wheel 'Are you goina put the ${ }^{\wedge}$ clay on', implemented through a question, is an initiating action which implicates that Mary should transfer the clay onto the wheel. Previous work on classroom settings has focused on how the child's response to a teacher's initiating action was occasionally delayed and was produced through supportive conduct from a learning support assistant (Stribling \& Rae, 2010). In the present setting, Mary's response does not come about straight away - but neither is it pursued or awaited by Mum. Rather, in this case, Mum launches an alternative activity (getting, and setting up, the pedal). Mary's response occurs while Mum is doing this, indeed it occurs in parallel with it. Although there is no evidence here that launching a side activity (getting the pedal) is a specific strategy to allow a child a space to respond to a just prior instruction, or that engagement in a side action might have a modelling function, it is notable that Mum refrains from pursuing a response from Mary. Routinely in social interaction, participants have a range of resources for pursuing a response from co-participants who have failed to provide one (Pomerantz, 1984). It is a feature of informal spontaneous activities that they involve parents having to address contingencies, such as dealing with an incomplete practical matter (here setting up the foot pedal); here it can be seen that addressing such contingencies can provide an opportunity space for a child to respond to an initiating action.

Throughout this extract then, Mary engages in task-relevant activities. For example, she is appropriately oriented to the potter's wheel and engages with 
it; she gets the clay following her Mum's instruction to do so. It is notable that she produces a task-related initiating action, instructing her mother to help with the activity, 'Mama help' (line 23). This does not appear to implicate assistance with an immediate difficulty but seems to work prospectively to indicate a requirement to assist with the later stages of the forthcoming activity. Nevertheless, Mum responds immediately with a reassuring reply, 'Yeah of course. I'm going to help'. The production of parental instructions is further illustrated in Extract 2 (this episode follows immediately from the stretch of activity presented in Extract 1).

\section{Extract 2 [MR2012 MM Clay] simplified}

\section{Continues immediately from Extract 1}

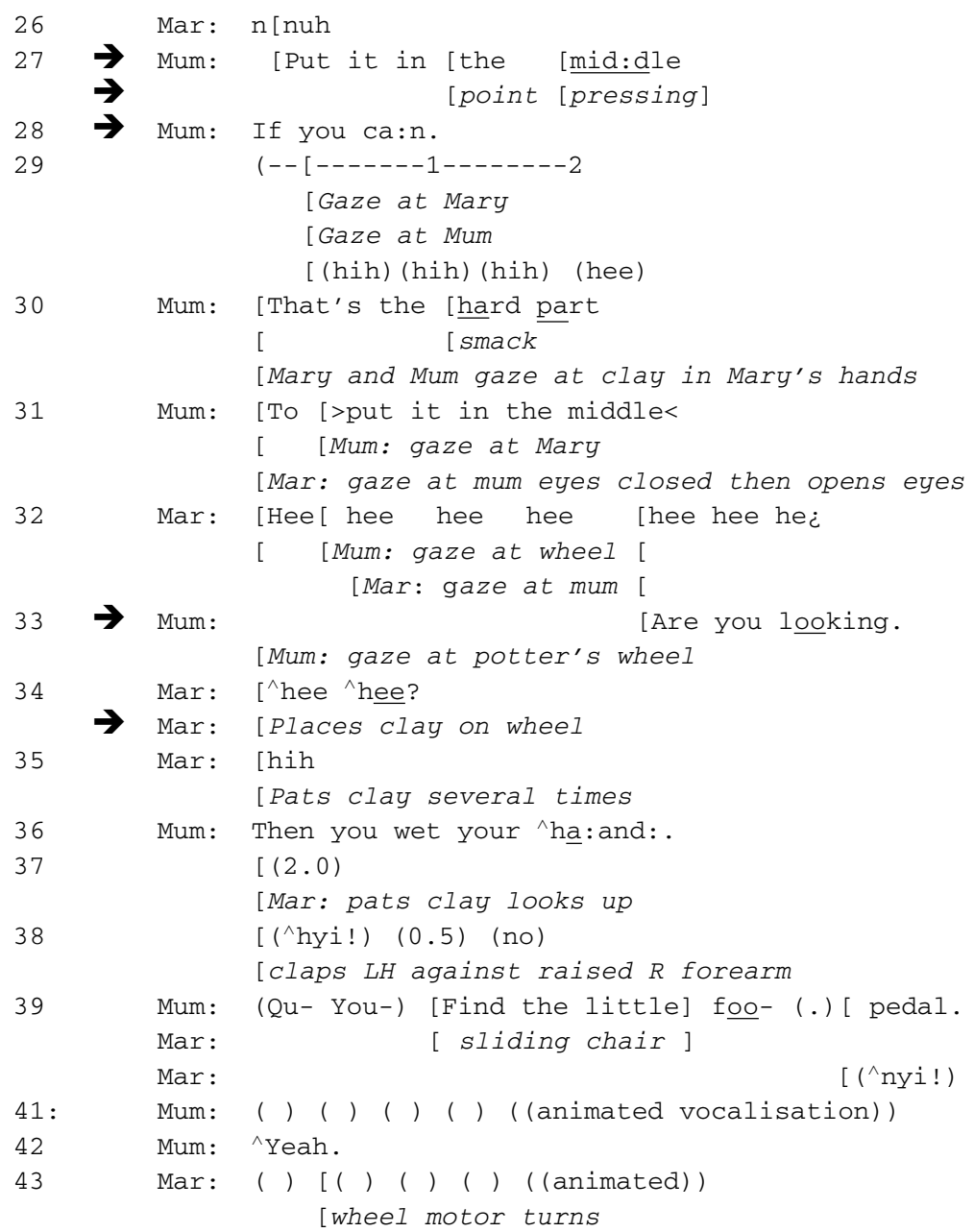




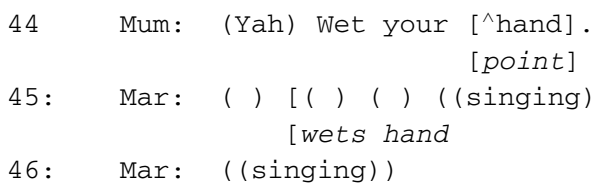

In Extract 2, both Mum and Mary are now seated and Mary has a ball of clay in her hands. Mum produces another action that is geared to progressing the task, the verbal instruction 'Put it' (i.e. the ball of clay) 'in the mid:dle' (i.e. in the centre of the wheel). As she says this, she points at the wheel bringing her pointing finger into a prominent contact-gesture which involves pressing the centre of the wheel. She extends her turn with the clause 'If you can', thereby extending the response space and perhaps indicating a lowering of her expectations that Mary can accomplish this. A spate of joint engagement follows which seems to be a site of positive affect with smiling and laughter. Mum again uses a question to progress the activity, gazing at the wheel she says 'Are you looking' (line 33), where upon Mary places the clay on the centre of wheel and pats it. It is notable that attentional gaze, together with this instruction to look, appears sufficient to direct Mary's focus of attention, and action, to the potter's wheel. Mum then produces an instruction in the form of a report 'Then you wet your hand' and then a direct instruction 'Find the little foo- (.) pedal' and 'Wet your hand' (pointing).

So far, the parental resources that we have examined involve the use of talk and gesture, in coordination with objects, to guide and direct the child's conduction. However, in Extract 3, Mum uses tactile resources to guide Mary's hands. First, she uses her left hand to guide Mary's right hand by holding the base of her hand (line 54), then she brings in her right hand to control Mary's fingers (line 55). She subsequently prompts Mary by saying 'And again on the si:ide' (line 59) simultaneously miming the required hand position.

\section{Extract 3 [MR2012 MM Clay] simplified}

Continues immediately from Extract 2

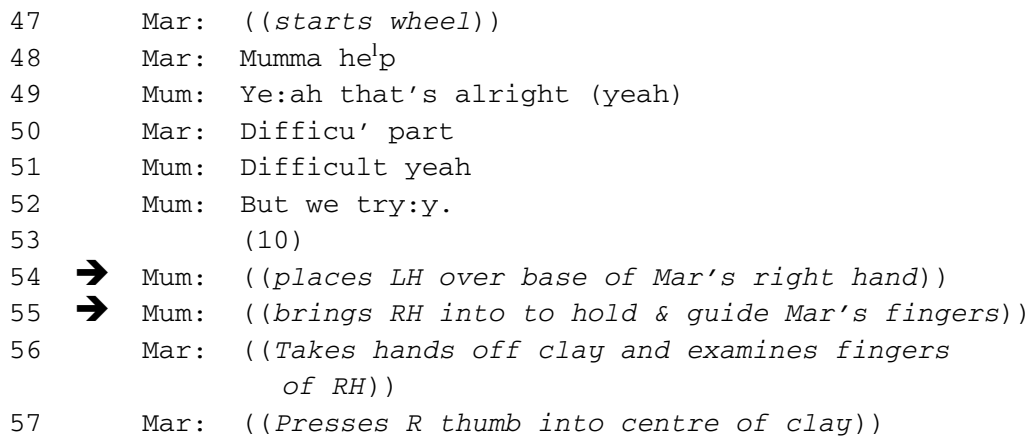




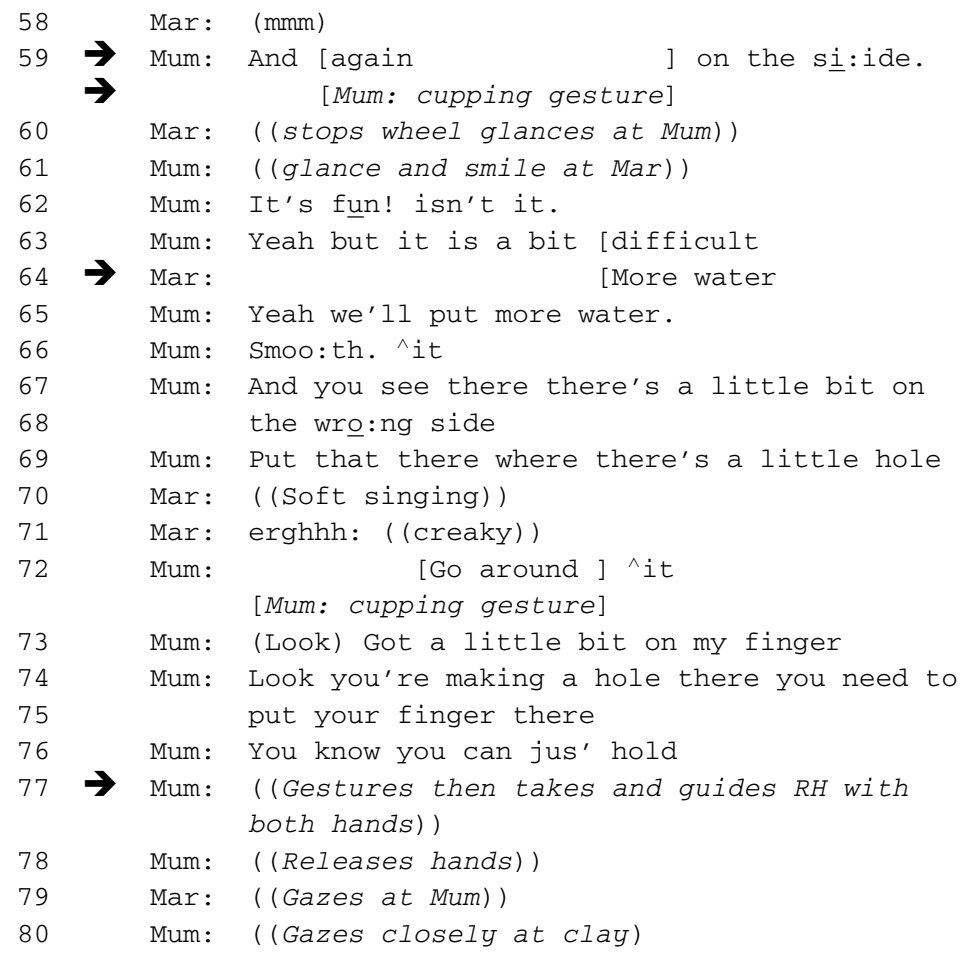

In Extract 4, which occurs towards the end of the activity, Mum engages in direct work on the clay pot herself; however, this involvement is highly collaborative in two respects. First, it comes about as a result of a request from Mary, Mary says 'Help' (line 2), pushing the wheel towards Mum (line 2) and pursues this request for help (line 5) with a prominent gesture. Mum seeks clarification 'Help doing hwha:t:' (line 7) and Mary provides it using talk and by gesturing towards a diagram. Secondly, Mum's direct involvement is collaborative in the sense that Mary controls the rotation of the wheel while her mother shapes the clay on the wheel; the work on the pot thereby being distributed between them.

\section{Extract 4 [MR2012 MM Clay] simplified}

8:55 into recording Mary has been smoothing the clay pot that she has formed, sometimes freehand, sometimes turning it on the wheel.

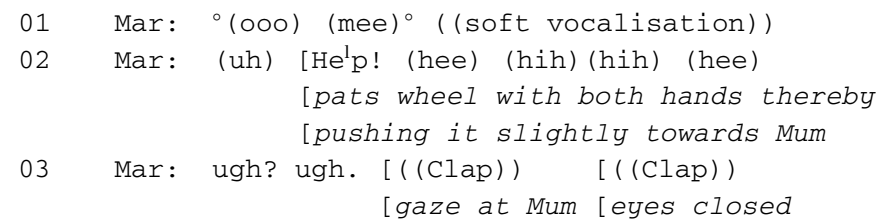




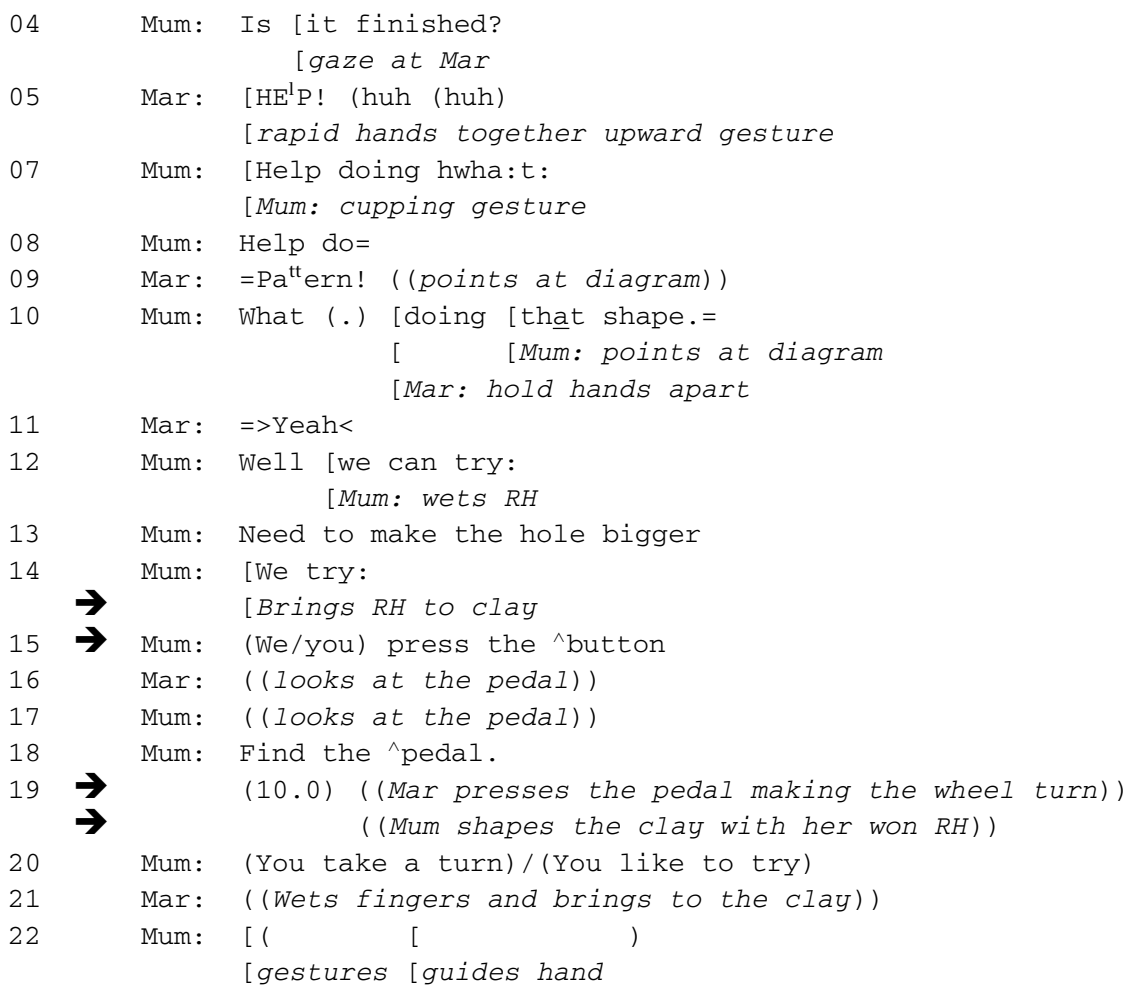

Across Extracts 1-4, and across the rest of pottery-making episode, several different classes of supportive conduct can be identified. Table 25.1 lists them in order of apparently increasing involvement.

The following section will consider further examples of (a) parents' resources for directing their children's attention; (b) parents' resources for prompting and pursuing responsive actions; and (c) parents' resources that are concerned with task-related contingencies and opportunities.

\section{Directing the child's attention}

In the pottery session, it is notable that the child has primary access to the objects through which the task is carried out. That is, the potter's wheel is placed directly in front of Mary and she apparently controls the foot pedal. As such, she is largely responsible for the progress of the task. By constrast in a kit construction task in which a boy, Benjamin, works with his Dad, the father places the box of components in front of himself and invites Benjamin to locate items from it and to fit them together. Despite the differences in this arrangement, and the difference in the nature of task itself (shaping clay as opposed 
Table 25.1 Classes of parent's supportive conduct

\begin{tabular}{rll}
\hline Action & Level of parental involvement \\
\hline 1 & Present, but otherwise engaged & Low \\
2 & Observing & \\
3 & Responding to questions or requests & \\
4 & Reassuring \\
5 & Commenting & \\
6 & Instructing (verbally) \\
7 & Instructing (using talk and gesture) \\
8 & Guiding child's hand \\
9 & Performing the task by guide the child's hand(s) \\
10 & Performing the task by physically directing the \\
& child's hand(s) & \\
11 & Performing part of the task directly & high \\
\hline
\end{tabular}

to assembling components), certain of the supportive practices located in the pottery episode occur here too. For example, the management of the child's attention can become an interactional concern.

Extract 5 is taken from an episode in which Benjamin ('Ben') and his father ('Dad') are seated at a table with a Lego calendar box. Dad has the Lego box in front of him, Benjamin is holding an electronic soundbox toy which is emitting a clapping sound effect. Dad produces an orienting remark and a summons (line 1) to which Benjamin responds with a vocalisation (lines 2-3); however, Benjamin remains engaged with the soundbox, pressing a button which produces a laughter and applause sound effect (shown as ' $\mathrm{xxx} . .$. '); as the soundbox emits this, Ben waves his hands (line 4).

\section{Extract 5 [MR2012 Benjamin \& Dad Table]}

Ben and Dad are seated side by side at a table, Dad is to Ben's right and has a Lego box open towards his right-hand side. Ben is handling a sound effects toy.

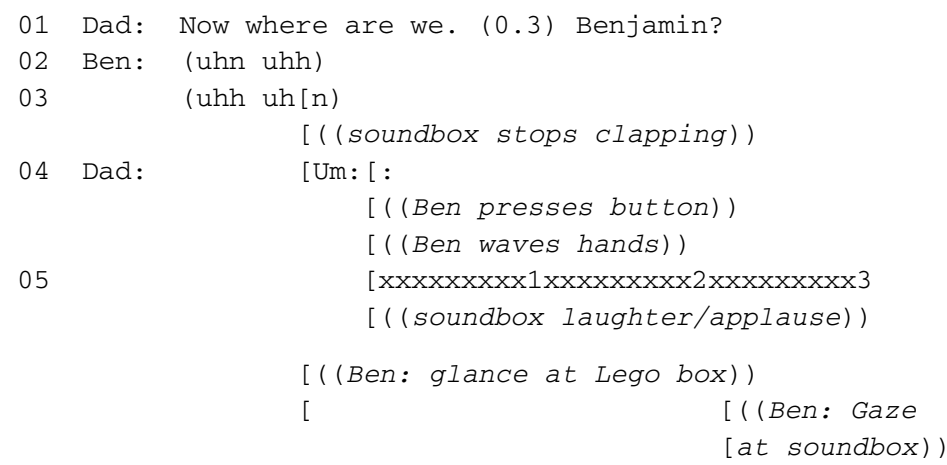




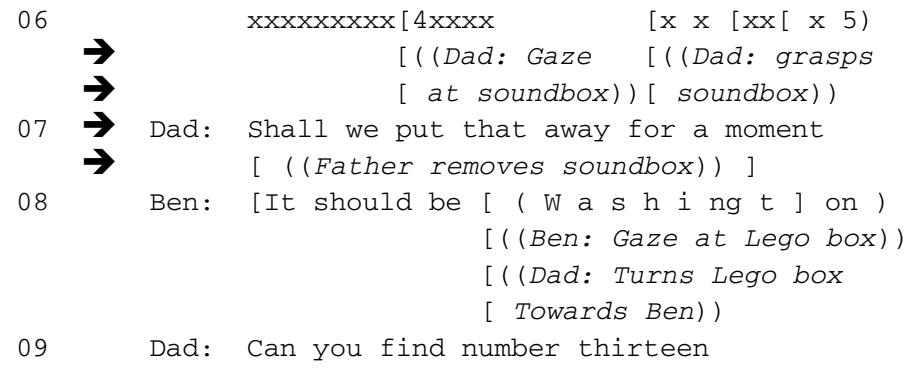

The father's practical problem here then is that Ben is not properly aligned with the proposed activity of playing with the Lego box. Dad's strategy is to remove the soundbox from Ben. First, he does not remove the box at once but allows for some time (about 4 seconds) to elapse before doing so (lines 5-6). It is notable that during this period Ben apparently shows some attention to the Lego box and glances at it briefly (line 6). Dad then brings his gaze to the soundbox, he takes it in his hand, and as he says 'Shall we put that away for a moment', he removes it from Ben. Ben appears to respond by producing an apparently unrelated vocalisation 'It should be Washington' (line 8) but he nevertheless brings his gaze to the Lego box such that Dad now considers it relevant to produce an activity-related instruction, 'Can you find number thirteen' (line 9). Consequently, we can see here that the father accomplishes the removal of the soundbox, and thereby accomplishes Ben's attending to the construction kit, in a progressive and accountable way.

\section{Prompting and pursuing responsive actions}

The issue of pursuing a response also occurs in the episode involving Ben and his Dad. Having produced the instruction 'Can you find number thirteen' (Extract 6, line 9), Dad waits for two seconds and then produces a simplified and emphasised repeat (Extract 6, line 11). Benjamin says, 'Thirteen wait' (line 13), thereby using vocal resources to show that although he has yet to produce the responsive action that has been implicated, he is nonetheless attending to it. In response to a further pursuit from Dad, 'Where's thirteen' (line 14), he produces an upscaled action to show that he is attending to the matter 'Way weh (.) wait a minute' (line 15). On the one hand, Ben's uses of vocal resources to display attention to the task of responding contrast with the use of tapping gestures that have been described in this sequential position (Dickerson, Stribling, \& Rae, 2007); however, his rapid co-occurring shake of his hand (line 15) bears some comparison with such tapping gestures. Thus here, Dad displays resources for pursuing a response, in this case largely verbal resources - and Ben displays resources for showing that he is relevantly attending. 


\section{Extract 6 [MR2012 Benjamin \& Dad Table]}

Follows from Extract 5.

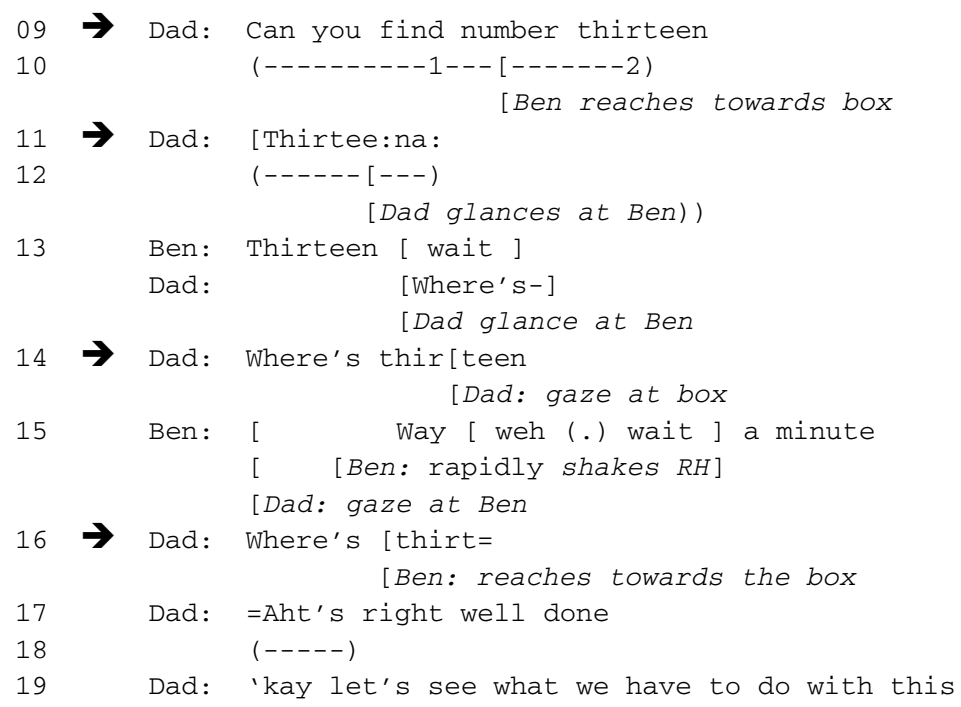

$\rightarrow$ Dad: $\quad[$ Thirtee:na:

(----------1--- [-------2)

[Ben reaches towards box

$\rightarrow$ Dad: Where's thir[teen

While Dad in Extract 6 is chiefly using verbal resources to prompt Ben to produce a nonverbal response (locating an object), Extract 7 demonstrates how a parent can use multimodal resources in order to elicit a verbal response. Extract 7 is drawn from an afternoon baking session organised by Mum for Will, her son, and Anna, a friend; both Will and Anna are 13 years old and diagnosed with autism. Here Will is getting the ingredients ready to make brownies with Mum's assistance.

\section{Extract 7 [Will \& Mum \& Anna Baking_I, We need flour]}

Anna is putting an apron on, Mum is has a recipe book in front of her on a worktop; Will is moving about.

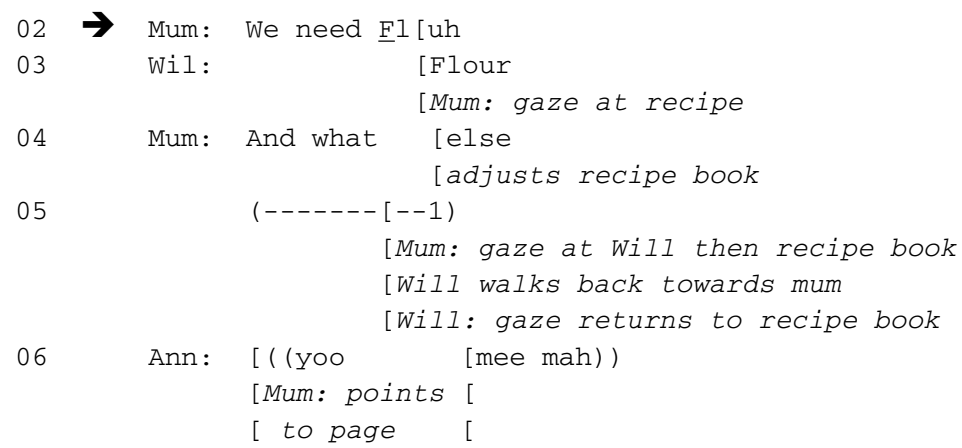




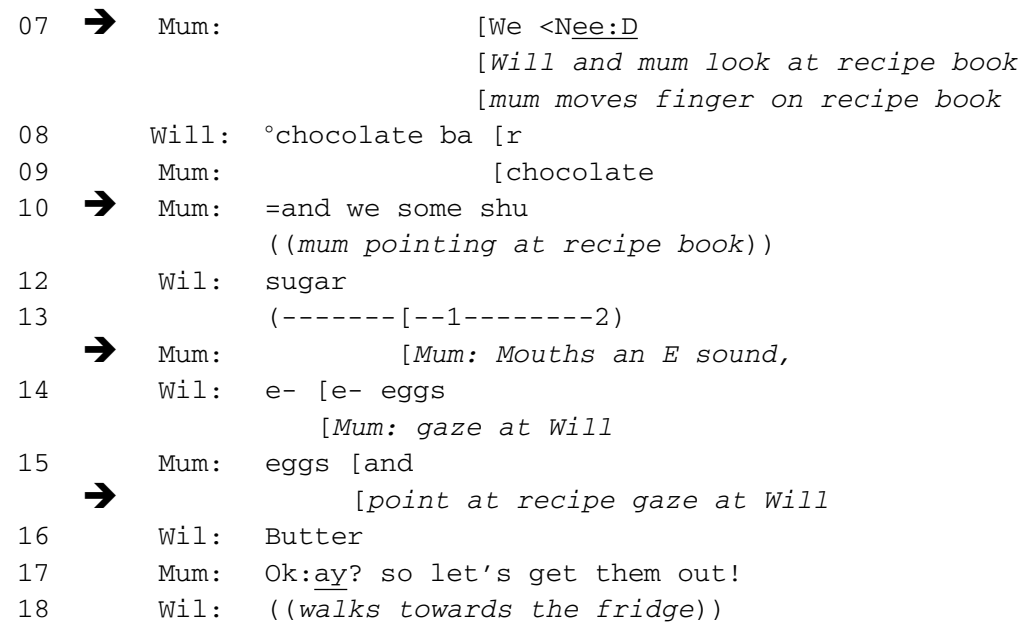

This episode takes place in the kitchen where Mum and Will are looking at the recipe book while Anna is putting on her apron. In line 1, Mum produces a model sentence by partially forming a sentence omitting the last utterance so that Will can complete it. This prompting technique has the same format as an intraverbal strategy used in behavioural-based approaches (Sundberg \& Michael, 2001). Will is gazing at the recipe book with his hand on Mum's shoulder. Will responds with 'Flour' while simultaneously moving away with his hand sliding off Mum's arm (line 3). As the task at hand is to collect all the ingredients to make brownies, it may be that Will wants to get the flour straight away. However, Mum repositions herself in front of the recipe book and points to the list of the ingredients and summons Will with 'and what else'. At this point, Anna who is present but not immediately involved in the exchange between Mum and Will engages in an echolalic utterance (line 5). Will returns and his gaze returns to the recipe book. Having secured Will's attention to the recipe book, Mum produces an incomplete sentence 'we need' while pointing at the recipe book. Will responds with 'chocolate bar' and Mum says 'chocolate' thereby confirming but also correcting Will's response. Mum then continues with another incomplete sentence for Will to complete 'and we need some shu' to which Will responds 'sugar'. For the next item in the list of ingredients, Mum just shapes her mouth to the ' $\mathrm{e}$ ' sound (for the response of eggs) and Will reads and responds 'e e eggs'. Mum confirms and continues with 'eggs and' whereupon Will reads and responds 'butter' without Mum prompting him. Mum confirms this item and indicates movement into a new activity with 'okay, so let's get them out'. Across this extract then, Mum uses a number of prompts to get Will to name the ingredients that they will need for the baking project. Consequently, his production of a list of the ingredients is scaffolded through Mum's prompts. Will responds quite readily to each prompt, so in this episode 
the pursuit of responses is limited. In most cases, these prompts are built out of a grammatically incomplete turn-at-talk coupled with gestures involving the recipe book; however, in the case of the item 'eggs', the prompt consists of a point at the recipe book. In this case, apparently in response to a latency in Will's responding, the mother pursues a response by mouthing the start of the required word. (As it happens, Will is not monitoring her and appears to produce his response independently of this pursuit.) While it is necessary to identify and retrieve the ingredients for the baking task, it is not necessary to enumerate a list of the ingredients together. Here then, Mum is creating an opportunity for Will's co-participation in the larger baking project where the task of the moment becomes listing the ingredients. This establishment of a local task exploits two general but contrasting properties of prompts, namely that there is a high degree of freedom about when they can be produced yet the range of relevant responses can be highly constrained. Furthermore, an interactionally important feature of prompts as supportive conduct is that they make the progress of the activity conditional upon the child's response. These features make prompts a potentially powerful and ubiquitous resource in supporting children's involvement in practical activities and in structuring those activities.

\section{Task-related contingencies and opportunities}

The issue of the parent being required to attend to a task-related contingency is also evident in the episode involving Ben and his Dad, as shown in Extract 8. It transpires that Dad's nomination of a particular component Part 13 is a mistake (lines 21, 23-25), and it becomes relevant to get this piece back from Ben. Having conveyed that they have already done this component, Dad reaches his left hand over to Ben's right hand in which he is holding Part 13 and then brings his right over and slides the component into it, producing an account as he does so 'Looks as though we've done it' (lines 26-27).

\section{Extract 8 [MR2012 Benjamin \& Dad Table]}

Follows from Extract 6

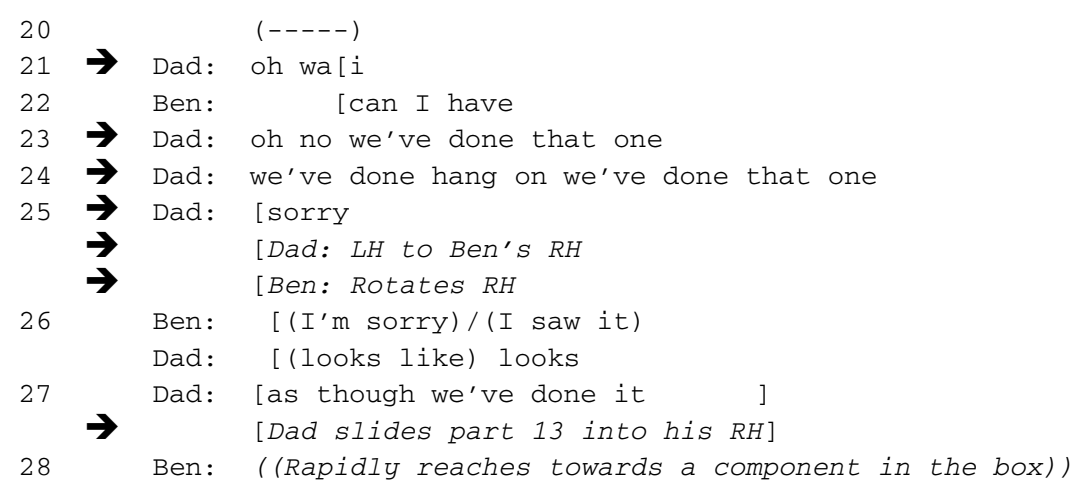


In Extract 1, the parent's engagement in a practical contingency provided an opportunity for action, on that occasion it provided a space for Mary to carry out a responsive action. In Extract 8, the nature of the contingency disrupts the progress of the activity - it involves having to hand back a part which it had taken some effort to locate. At just this point, Ben darts to locate another component in the box; thus it appears that addressing the contingency that arose disrupts the joint progress on the task that had recently been established. Extract 9, drawn from the baking session, further suggests that breaks in the progress of an activity can lead to momentary disruptions. Here William has retrieved a box of eggs and has been waiting with them while Mum had to attend to something else. It occurs to Mum that it is desirable to use up some older eggs first. She swiftly brings out these newer eggs and puts away the ones that William had retrieved. At just this moment, William covers his ears and then begins engaging in self-stimulatory behaviour, rubbing his cheeks, and jumping up and down. Although we cannot be clear about the causal link on this single case, it appears that the change to the trajectory of this task (i.e. the substitution of the eggs) has created some disruption that has occasioned this self-stimulatory behaviour.

Extract 9 [Will and Anna baking] $<1: 35>$

William is standing at the kitchen counter with the egg box that got out a minute ago. Mum comes back from having helped a younger sibling with another project.

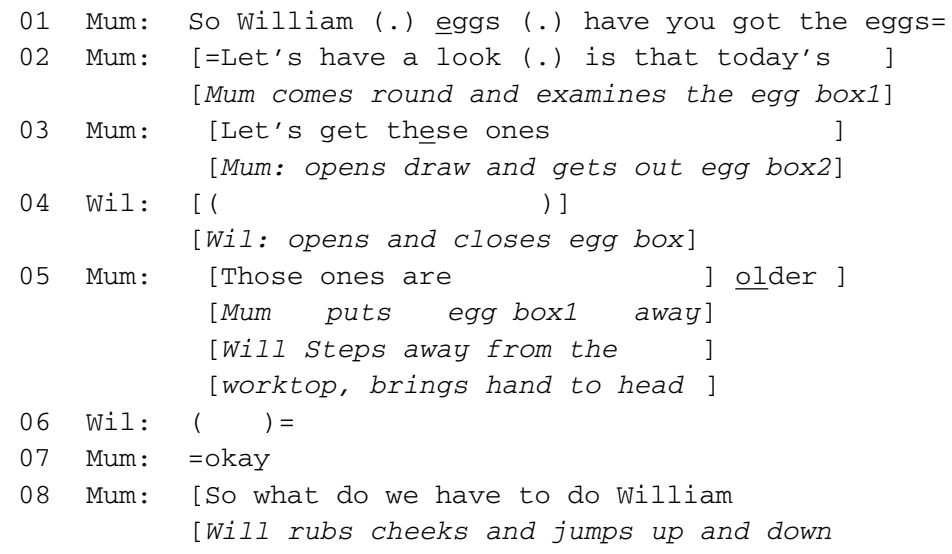

Domestic activities then, in contrast to more routine educational tasks, can involve contingencies where objects need to be located or substituted. A key difference can be seen within this class of occurrences. On the one hand, there are cases where a parent's addressing a contingency occurs at a moment where a child is occupied in something else and the parent's engagement with another 
matter does not disrupt the child. On the other hand, where the parent needs to remedy a state of affairs that the child has brought about, remediation becomes the joint activity of the moment. A parallel is seen here with the talk-based phenomena of exposed and embedded correction (Jefferson, 1987). In exposed correction, one speaker corrects another speaker by producing a turn that is dedicated to carrying out correction, thus correction comes to the surface of the interaction. Indeed, the action of correcting becomes the activity of the moment, and the progression of the activity that was in progress is temporarily suspended. By contrast, in embedded correction, one speaker produces a turn that responds to another speaker's turn, but in the course of producing that turn embeds the correction of a component of the turn to which they are responding. The activity that was underway is thereby progressed, with correction being carried out in passing.

A further kind of contingency involves taking an opportunity to engage in a stretch of action which is relevant, but not immediately necessary for, a course of action that is in progress. For example, in the baking session, Extract 10, Mum takes the opportunity to appreciate the mixture that they have created. Within this bout of activity, she initiates a sequence by asking Will 'Is it nice' (line 5) to which he replies 'Delicious' (line 6), thereby achieving a moment of shared appreciation. Such sequences of actions are essentially side sequences (Jefferson, 1972).

\section{Extract 10 [MR2012 WMA] (05:34) (Schematic)}

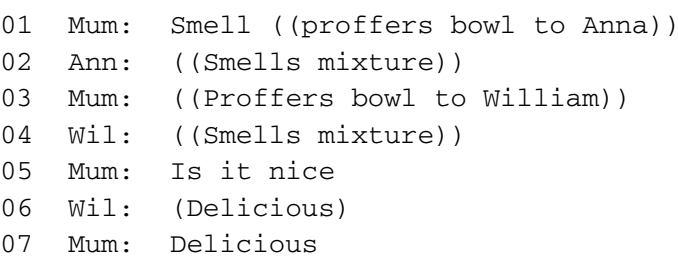

\section{Discussion}

Across the episodes examined, the parents show their use of a range of practices for supporting their children in domestic, practical activities. As with the practices identified in the work of a learning support assistant (a participant who has an institutional job to provide support) (Stribling \& Rae, 2010), these practices are richly multimodal and commonly have a contingent and progressive character. That is, they are commonly carried when they become contingently relevant and their degree of directiveness can be scaled up, or down, as becomes as necessary. Some practices, such as Mary's Mum guiding Mary's hand on the potter's wheel, are highly directive but nonetheless require appropriate participation 
from Mary: both in terms of allowing her hand to be guided and also in terms of operating the pedal to control the wheel. Others pose questions for the child to solve. For example, when Mum gazes at the potter's wheel and asks 'Are you looking?', Mary has to work out the practical relevance of this gestalt, this particular configuration of utterance, gaze, and object. Similarly, when Will's Mum points at the recipe book and says 'what else?' this is not informative statement delivering concrete information; its import is to be found in the current course of action (Garfinkel, 2002). Will comes back towards his mother and gazes at the book thereby disentangling his mother's question, her pointing, and her eye-gaze.

\section{Clinical relevance summary}

This analysis has described a number of practices that are spontaneously used in a small opportunity sample from families who consented to take part in this research. Further research, with a larger sample, is necessary to establish the generality of the practices used and to assess their effectiveness. The study does, however, provide some examples of contingencies that are commonly encountered and of the practices used by parents in addressing them. Furthermore, there are some interesting implications for practice with children diagnosed with ASD and their families. Our analysis has demonstrated that parents use many different resources for supporting children with their everyday tasks and this could involve directing the child's attention or prompting responsive actions. Furthermore, there were different ways of dealing with task-related contingencies and opportunities. This shows how parents can create opportunities for facilitating and promoting participation within the interaction. For a simple summary of the implications for practice, see Table 25.2.

\section{Summary}

Fundamentally then, the parents' tasks in carrying out everyday practical activities with their children, as in much social interaction, consists in deciding how to co-participate with the unfolding events (Goodwin, 2007). In these settings,

\section{Table 25.2 Clinical practice highlights}

1. Parents' resources for supporting children carrying out everyday tasks involve (a) directing the child's attention, (b) prompting and pursuing responsive actions, and (c) ways of dealing with task-related contingencies and opportunities.

2. An important class of activities involves creating opportunities for various forms of participation (by the parent or child) which are not directly supportive of the child's conduct, but which allow for the progression of the task or which manage the child's involvement with it. 
the parents draw on interactional resources in order to accomplish the practical management of their child's distinctive ways of seeing the world and acting within it, their autistic intelligence (Maynard, 2005). It seems likely that some of the practices used, such as Mary's Mum's use of manual guidance, or her question 'Are you looking?', and Will's Mum's vocalisations for the beginnings of words, are adaptations of ABA prompts, but it is beyond the scope of the current study to establish this. Certain practices however are neither prompts nor are they scaffolding. The term 'scaffolding' implies supportive conduct, that is actions that are done in order to support or assist the child. However, an important class of activities involve creating opportunities for various forms of participation (by the parent or child) which are not directly supportive but which allow for the progression of the task or which manage involvement with it. This study is clearly limited. Further work is needed to better understand parents' resources and their effectiveness.

\section{Acknowledgements}

We greatly appreciate the help of the children and parents who have contributed to this project, without whom it would not have been possible. An earlier version of this presentation was given at ICCA 2014 at UCLA; we're grateful for the comments received there. Thanks also to Mats Andrén for helpful comments.

\section{References}

Applebee, A. N., \& Langer, J. A. (1983). Instructional scaffolding: Reading and writing as natural language activities. Language Arts, 60, 168-175.

Barron, B. (2006). Video as a tool to advance understanding of learning and development in peer, family and other informal learning contexts. In R. Goldman, R. Pea, B. Barron, \& S. J. Derry (Eds.), Video research in the learning sciences (pp. 159-187). Routledge: Abingdon.

Brown, A. L., \& Palincsar, A. S. (1989). Guided, cooperative learning and individual knowledge acquisition. In L. B. Resnick (Ed.), Knowing, learning and instruction: Essays in honor of Robert Glaser (pp. 393-451). Hillsdale, NJ: Lawrence Erlbaum Associates.

Carr, A., \& Pike, A. (2012). Maternal scaffolding behaviour: Links with parenting style and maternal education. Developmental Psychology, 48(2), 543-551.

Dickerson, P., Stribling, P., \& Rae, J. (2007). Tapping into interaction: How children with autistic spectrum disorders design and place tapping in relation to activities in progress. Gesture, 7, 271-303.

Ekström, A., Lindwall, O., \& Säljö, R. (2009). Questions, instructions, and modes of listening in the joint production of guided action: A study of student-teacher collaboration in handicraft education. Scandinavian Journal of Educational Research, 53(5), 497-514.

Freeman, S., \& Kasari, C. (2013). Parent-child interactions in autism: Characteristics of play. Autism, 17(2), 147-161.

Garfinkel, H. (2002). Ethnomethodology's program: Working out Durkheim's aphorism. Lanham, MD: Rowman \& Littlefield. 
Goodwin, C. (2007). Participation, stance and affect in the organization of activities. Discourse Society, 18(1), 53-73.

Goodwin, C., \& Heritage, J. (1990). Conversation analysis. Annual Review of Anthropology, $19,283-307$

Jefferson, G. (1972). Side sequences. In D. N. Sudnow (Ed.), Studies in social interaction (pp. 294-33). New York: Free Press.

Jefferson, G. (1987). On exposed and embedded correction in conversation. In G. Button \& J. R. E. Lee (Eds.), Talk and social organization (pp. 86-100). Clevedon, UK: Multilingual Matters.

Kasari, C., Gulsrud, A. C., Wong, C., Kwon, S., \& Locke, J. (2010). Randomized controlled caregiver mediated joint engagement intervention for toddlers with autism. Journal of Autism and Developmental Disorders, 40(9), 1045-1056.

Krantz, P. J., \& McClannahan, L. E. (1998). Social interaction skills for children with autism: A script-fading procedure for beginning readers. Journal of Applied Behavior Analysis, 31(2), 191-202.

Langer, J. A., \& Applebee, A. N. (1986). Reading and writing instruction: Toward a theory of teaching and learning. In E. Z. Rothkopf (Ed.), Review of research in education (Vol. 13, pp. 171-194). Washington, DC: American Educational Research Association.

Lindwall, O., \& Ekström, A. (2012). Instruction-in-interaction: The teaching and learning of a manual skill. Human Studies, 35(1), 27-49.

MacDuff, G. S., Krantz, P. J., \& McClannahan, L. E. (2001). Prompts and prompt-fading strategies for people with autism. In C. Maurice, G. Green, \& R. M. Foxx (Eds.), Making a Difference: Behavioral Intervention for Autism (pp. 37-50). Austin, TX: Pro-ed.

Maynard, D. W. (2005). Social actions, gestalt coherence, and designations of disability: Lessons from and about autism. Social Problems, 5, 499-529.

Mondada, L. (2014). Instructions in the operating room: How the surgeon directs their assistant's hands. Discourse Studies, 16(2), 131-161.

Pomerantz, A. (1984). Pursuing a response. In J. M. Atkinson \& J. Heritage (Eds.), Structures of social action: Studies in conversation analysis (pp. 152-163). Cambridge: Cambridge University Press.

Salonen, P., Lepola, J., \& Vauras, M. (2007). Scaffolding interaction in parent-child dyads: Multimodal analysis of parental scaffolding with task and non-task oriented children. European Journal of Psychology of Education, 22(1), 77-96.

Schegloff, E. A. (2007). Sequence organization in interaction: A primer in conversation analysis (Vol. 1). Cambridge: Cambridge University Press.

Schegloff, E., \& Sacks, H. (1973). Opening up closings. Semiotica, 8(4), 289-327.

Stone, C. A. (1998). The metaphor of scaffolding its utility for the field of learning disabilities. Journal of Learning Disabilities, 31(4), 344-364.

Stribling, P., \& Rae, J. (2010). Interactional analysis of scaffolding in a mathematical task in ASD. In H. Gardner \& M. Forrester (Eds.), Analysing interactions in childhood insights from conversation analysis (pp. 185-208). New York: Wiley.

Sundberg, M. L., \& Michael, M. (2001). The benefits of Skinner's analysis of verbal behaviour for children with autism. Behaviour Modification, 25, 678-724.

Vygotsky, L. S. (1978). Mind in society: The development of higher psychological processes. Cambridge, MA: Harvard University Press. (Original manuscripts [ca. 1930-1934].)

Wood, D. J. (1980). Teaching the young child: Some relationships between social interaction, language, and thought. In D. R. Olsen (Ed.) The Social Foundations of Language and Thought (pp. 280-296). New York, NY: Norton. 
Wood, D., Bruner, J., \& Ross, G. (1976). The role of tutoring in problem solving. Journal of Child Psychology and Child Psychiatry, 17, 89-100.

Zemel, A., \& Koschmann, T. (2014). 'Put your fingers right in here': Learnability and instructed experience. Discourse Studies, 16(2), 163-183.

\section{Recommended reading}

- Stone, C. A. (1998). The metaphor of scaffolding and its utility for the field of learning disabilities. Journal of Learning Disabilities, 31(4), 344-364.

- Tarplee, C., \& Barrow, E. (1999). Delayed echoing as an interactional resource: A case study of a 3-year-old child on the autistic spectrum. Clinical Linguistics \& Phonetics, 13, $449-482$.

\section{Transcription codes}

The notation scheme used in for these data was originally developed by Gail Jefferson. For further explanation of Jefferson's transcription conventions, see Jefferson, G. (1984) Transcription notation. In Atkinson, J. \& Heritage, J. (Eds.) Structures of Social Action (pp. ix-xvi). New York: Cambridge University Press. Superscribed letters, as in Mary's rendering of 'help', shown as 'hel $\mathrm{p}^{\text {', are used }}$ to show sounds that are partially present, for example which condition the pronunciation of other sounds in the word but are not fully expressed. 